\title{
Magnetic properties of silicon steel sheet core with different processing stress
}

\author{
Toshiki Matsui ${ }^{1}$, and Kyyoul Yun ${ }^{1, *}$ \\ ${ }^{1}$ Gifu University, Faculty of Engineering, 1-1 Yanagido Gifu, Japan
}

\begin{abstract}
The motor core including a rotor core and a stator core, which is made from silicon steel sheets. Iron loss increases during fixation of the stator core, e.g., by interlocking, welding, and shrink fitting installation. In this paper, the magnetic properties changes by each processing such as wire cutting, punching, interlocking and shrink fitting are investigated. Iron loss of the toroidal cores using punching, interlocking and shrink fitting are increased from $1.16 \mathrm{~W} / \mathrm{kg}$ to $1.56 \mathrm{~W} / \mathrm{kg}(34.4 \%$ increased) at $50 \mathrm{~Hz}$, and from $21.1 \mathrm{~W} / \mathrm{kg}$ to $27.5 \mathrm{~W} / \mathrm{kg}$ (30.3\% increased) at $400 \mathrm{~Hz}$ compared with iron loss of wire cut toroidal core.
\end{abstract}

\section{Introduction}

Modern society requires a huge amount of energy, especially clean and highly adaptable electrical energy. The highest electricity consumers in modern society are rotating machines, which have an electricity usage rate of over $57.3 \%$. Rotating machines have industrial, commercial, and household applications, because of their high efficiency and handiness. Therefore, an increase in rotating machine efficiency leads to huge amounts of electrical energy savings realized in megawatts [1]. Magnetic hysteresis curves are affected by the residual stress (mainly compressive stress) of the material [2, 3]. The motor core includes a rotor core and a stator core, which are made from electrical steel sheets. Iron loss increases during fixation of the stator core, e.g., by interlocking (mechanical bonding), welding, and thermal insert installations [4-9]. These methods produce a residual stress in the motor core, leading to an increase in the building factor and iron loss of the motor. To realize a high-efficiency motor, the residual stress of the motor core must be figured the process out of the interlocking, welding or the shrink fitting of the core for the motor. In this paper, the magnetic properties affected by residual stress such as wire cutting, punching, interlocking and shrink fitting.

\section{Experimental procedure}

\subsection{Specimen}

Ring-shaped silicon steel sheets were prepared by four types of process such as (i) wire cutting, (ii) punching, (iii) interlocking and (iv) shrink fitting after (iii). The material used is 35A270 (Nippon steel \& Sumitomo metal), and each silicon steel sheets has $50 \mathrm{~mm}$ in outer diameter and $40 \mathrm{~mm}$ in inner diameter. And then toroidal cores were prepared by 10 sheets lamination. Magnetic properties are affected by various stress. To prevent it, toroidal cores were set on in a frame, which made from Bakelite $0.2 \mathrm{~mm}$ diameter larger than outer diameter of ring shaped silicon steel sheet as shown in Fig 1 (a). Thickness of Bakelite frame was $1 \mathrm{~mm}$. Excitation coil was 200 turns and B coil was 100 turns. Excitation wave form was sinusoidal curve. Maximum magnetic flux density was $1.0 \mathrm{~T}$. In order to separate iron loss DC hysteresis loss and eddy current loss from iron loss. DC magnetization equipment and $\mathrm{AC}$ magnetization equipment were used. Frequency of AC measurement was $50 \mathrm{~Hz}$ and $400 \mathrm{~Hz}$. To realize the effect of shrink fit, SUS 304 frame was used as shown in Fig.1 (b). Diameter of outer SUS frame was $0.1 \mathrm{~mm}$ radially shorter than a dimeter of toroidal core. Both frames have $6 \mathrm{~mm}$ in height and $52.2 \mathrm{~mm}$ in outer diameter. To investigate an insulation between SUS frame and toroidal core, insulating tape (12 $\mu \mathrm{m}$, thickness) was used in boundary surface.

Magnetic properties of silicon steel sheets are easy to deteriorate by residual stress. Therefore, it is important to suppress the effect of the stress from coil winding. To prevent of coil winding effect, Bakelite cases were prepared as shown in Fig. 1. Thickness of the Bakelite cases is $1 \mathrm{~mm}$, and diameter of the case are 50.2 $\mathrm{mm}$ in inner diameter of upper case and $39.9 \mathrm{~mm}$ in outer dimeter of lower case.

Figure 2 shows the diagram to reproduce the processing of thermal insert. Nonmagnetic material of case is SUS304 to prevent the additional permeability from case. To add the compressive stress, diameters of the case are $49.9 \mathrm{~mm}$ in inner diameter of upper case and $39.8 \mathrm{~mm}$ in outer dimeter of lower case.

* Corresponding author: yun7110@gifu-u.ac.jp 


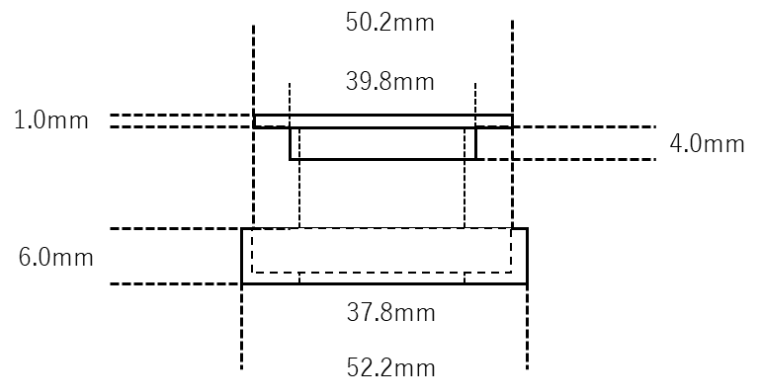

(a) Bakelite.

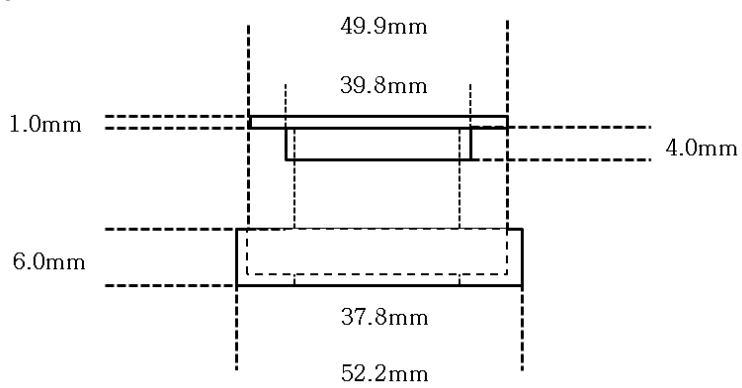

(b) SUS304.

Fig. 1. Frame to prevent stress and shrink fitting.

\subsection{Experimental equipment}

In this time, to separate the total iron loss with DC hysteresis loss and eddy current loss, two different equipment are used. One of them is DC magnetization equipment to measure the DC magnetic properties. The other one is $\mathrm{AC}$ magnetization equipment. The diagram of $\mathrm{AC}$ experimental equipment is represented in Fig. 2. The exciting coil with a $1 \mathrm{~mm}$ wire diameter is wound in two layers with 200 turns. The iron loss $(W)$ was calculated as follows:

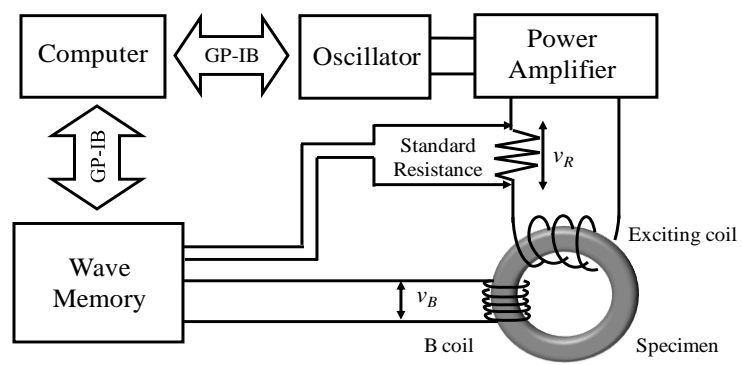

(a) AC measurement system.

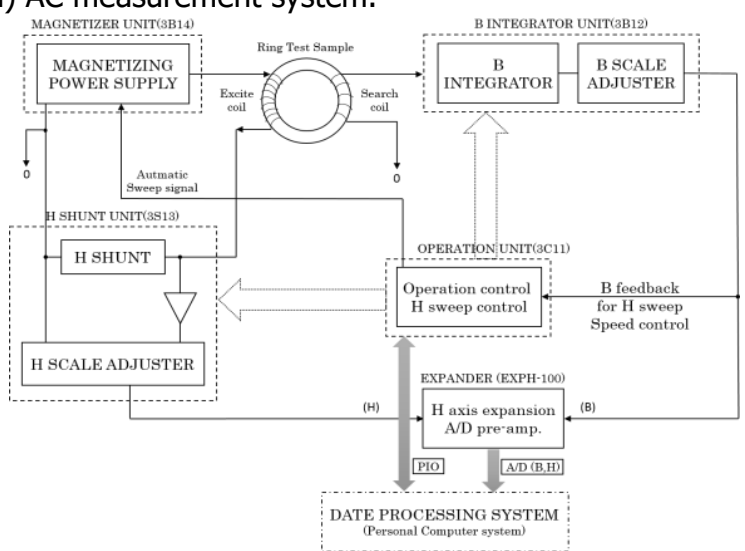

(b) DC measurement system.

Fig. 2. Diagram of experimental equipment.

$$
W[W / k g]=\frac{1}{\rho T} \int_{0}^{T} H \frac{d B}{d t} d t
$$

where $\rho$ was the density of the specimen and $T$ was the cycle. Form factor of excitation wave form was $1.11 \pm$ 0.01 .

\section{Results and discussions}

From Fig. 3, shrink fitting has the largest hysteresis loop and the largest iron loss value. Then the iron loss value is decreases in the order of shrink fitting, interlocking, punching and wire cutting. The coercively force $\left(H_{c}\right)$, the maximum magnetic field $\left(H_{m}\right)$ and relative permeability $\left(\mu_{r}\right)$ were compared at $50 \mathrm{~Hz}$. The wire cutting was $H_{c}=$ $48[\mathrm{~A} / \mathrm{m}], H_{m}=131.84[\mathrm{~A} / \mathrm{m}]$ and $\mu_{r}=6041$. The punching was $H_{c}=58[\mathrm{~A} / \mathrm{m}], H_{m}=325.21[\mathrm{~A} / \mathrm{m}]$ and $\mu_{r}$ $=2453$. The interlocking was $H_{c}=63[\mathrm{~A} / \mathrm{m}], H_{m}=$
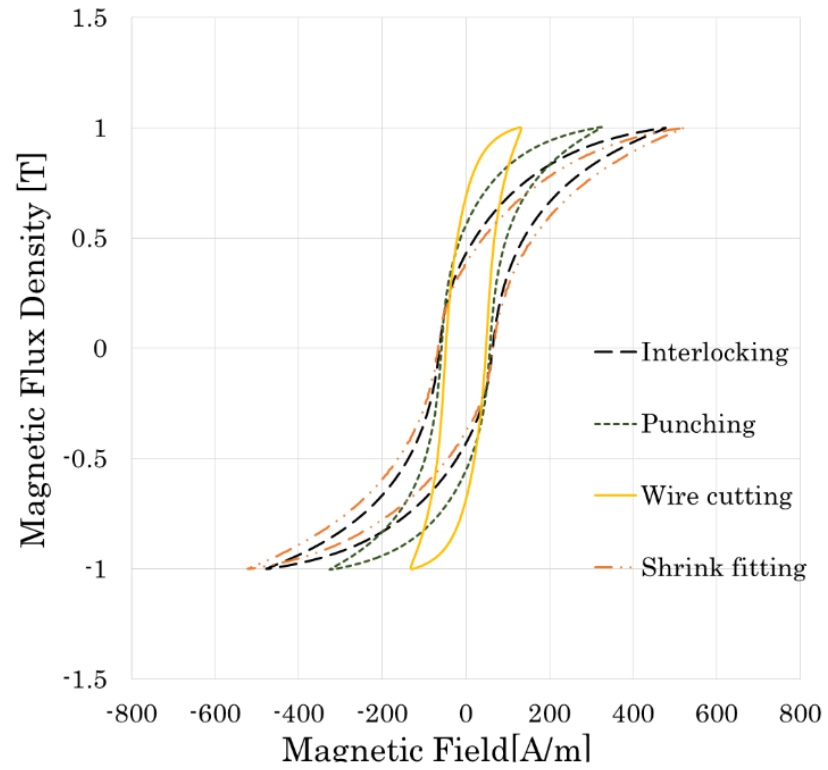

(a) Magnetic hysteresis curves at $50 \mathrm{~Hz}$.

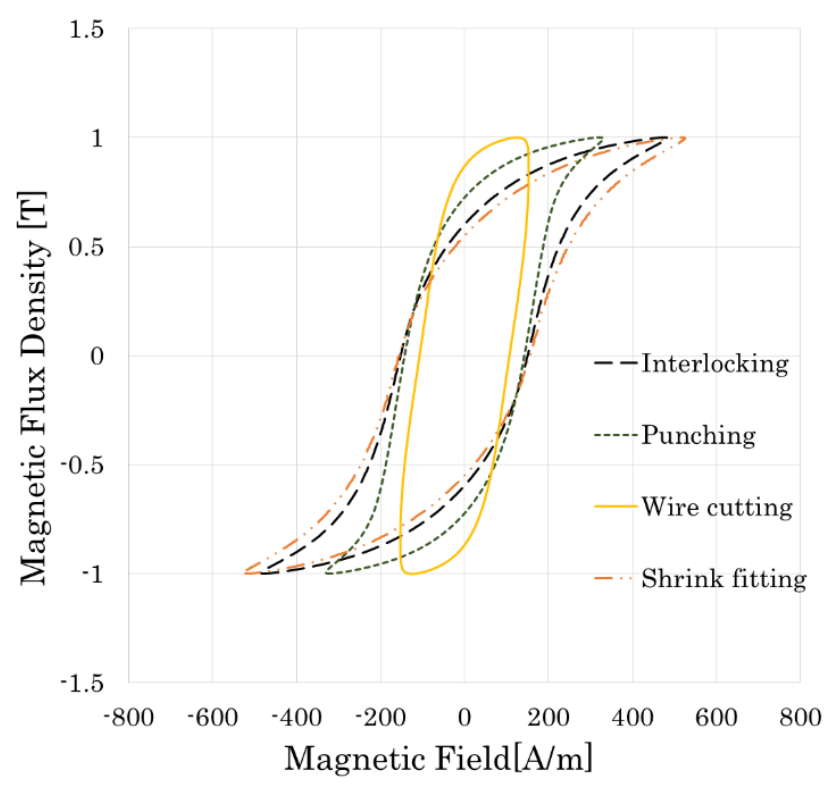

(b) Magnetic hysteresis curves at $400 \mathrm{~Hz}$.

Fig. 3. Magnetic hysteresis curves with $50 \mathrm{~Hz}$ magnetization. 
477.66 $[\mathrm{A} / \mathrm{m}]$ and $\mu_{r}=1667$. The shrink fitting was $H_{c}=$ $65.25[\mathrm{~A} / \mathrm{m}], H_{m}=521.44[\mathrm{~A} / \mathrm{m}]$ and $\mu_{r}=1525$. From the results, magnetic properties using wire cutting show the smallest coercive force and maximum magnetic field, maximum permeability is the highest. It can be seen that the coercive force is increased with each processing and the characteristics of the soft magnetic material deteriorate.

Iron loss of wire cutting shows the lowest value. The eddy current loss of the wire cutting at $50 \mathrm{~Hz}$ is larger than that of the punching specimen, but at $400 \mathrm{~Hz}$ the wire cutting specimen has the smallest value. As a result, deterioration of magnetic characteristics with wire cutting is smaller than that with punching. Also, it can be seen that hysteresis loss due to shrink fitting is smaller than interlocking. Due to stress caused by interlocking deterioration can be reduced by shrink fitting the punching specimen. What can be seen from the above graphs and tables is that the processing stress due to the cutting method when forming a ring sample has the most influence on the magnetic characteristics, and the iron

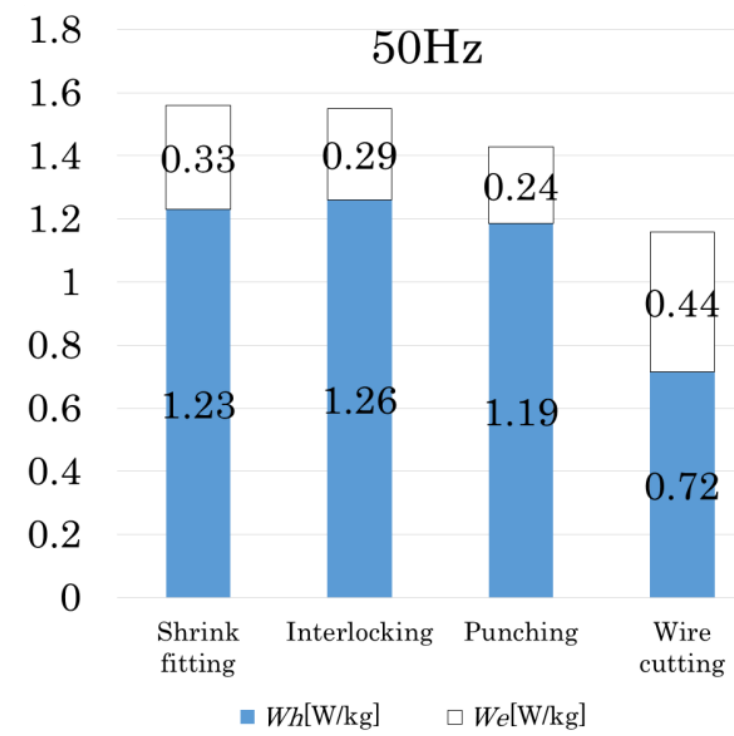

(a) Iron loss saperation at $50 \mathrm{~Hz}$.

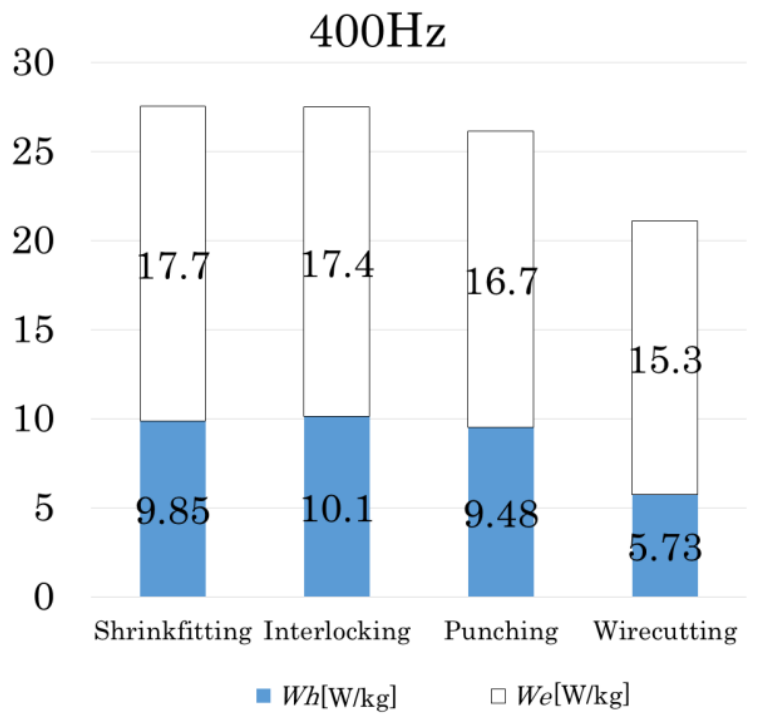

(b) Iron loss saperation at $50 \mathrm{~Hz}$.

Fig. 5. Magnetic hysteresis curves with $400 \mathrm{~Hz}$ magnetization. loss is increased by $24 \%$ in the punching process as compared with the wire cutting. Toroidal core of interlocking has an iron loss of $5 \%$ higher than that of punched core. Although the crimped sample was used as the shrinkage fitting sample, the iron loss value

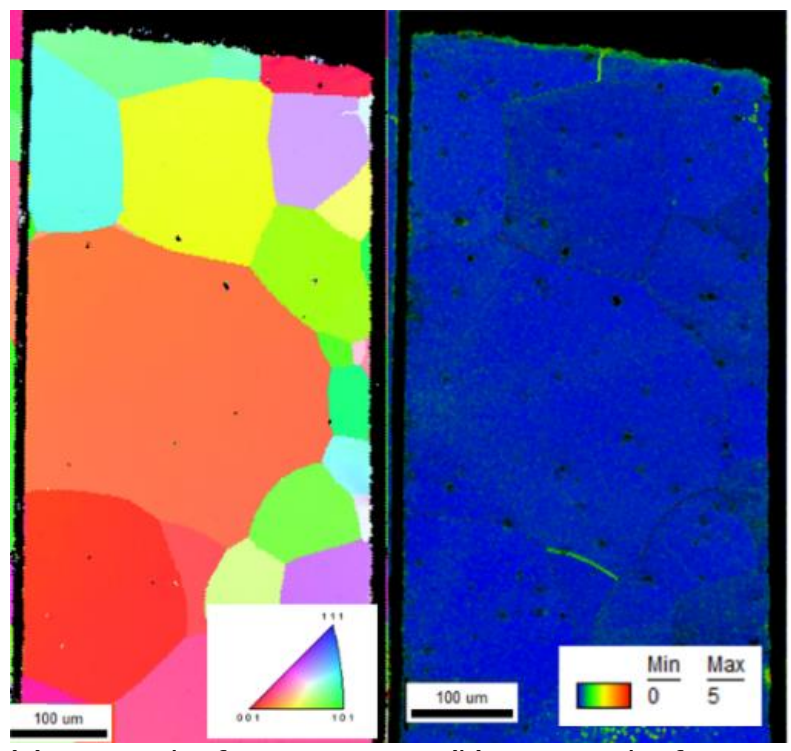

(a) IPF result of wire cut. (b) KAM result of wire cut.
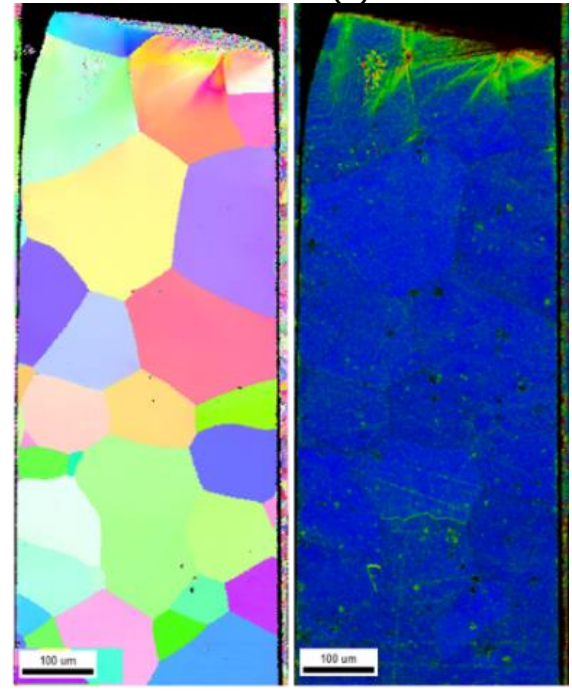

(c) IPF result of punching.

(d) KAM result of punching.

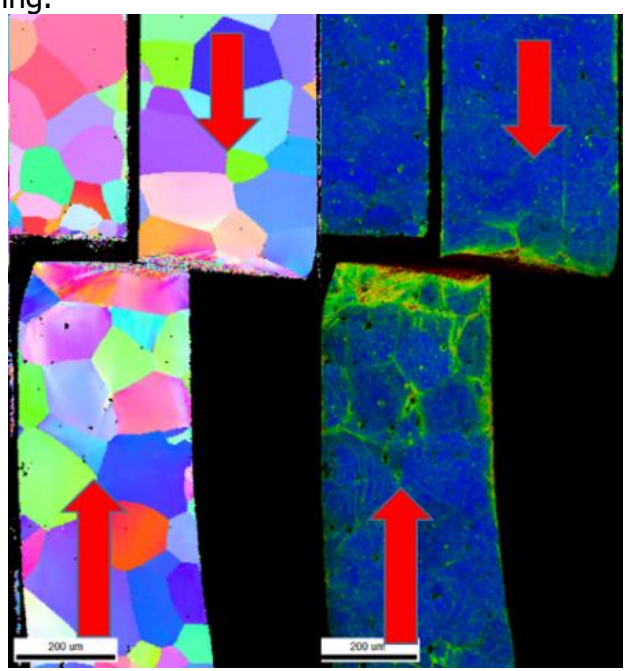


(e) IPF result of interlocking. interlocking.

Fig. 5. Iron loss of each process.

increased by $7 \%$. There is an increase in core loss value of $12 \%$ by carrying out all the steps from punching to shrink fitting. Considering hysteresis loss and eddy current loss $50 \mathrm{~Hz}$ due to iron loss separation with reference to wire cut. Hysteresis loss of wire cutting toroidal core is $65.5 \%$ and $76.1 \%$ smaller than that of punched toroidal core and interlocked toroidal core, respectively.

IPF and KAM results of each processing stress are shown in Fig.5. In the IPF diagram of the wire cutting (fig.5 (a)), the crystal orientation of the crystal grain at the cutting portion are not changed by wire cutting. Therefore, the iron loss of the wire cutting toroidal core shows the minimum value. Also in the KAM diagram (fig.5 (b)), the distortion at the incision is several $\mu \mathrm{m}$ at the sample edge. It means that the residual stress is not occured by wire cutting. In the IPF diagram of punching (fig.5 (c)), and residual stress was confirmed in crystal grains of about $200 \mu \mathrm{m}$ from the edge of the sample. Also in the KAM diagram (fig.5 (d)), it can be seen that a strain of about $200 \mu \mathrm{m}$ is generated from the sample end. The crystal grains around the cutting portion by the punching shows a fine-grained crystals compare with that by wire cut. Therefore, magnetic path is possible to change and get longer by the fine crystal grain. It means that the magnetic properties are deteriorated by punching. It is clear from the IPF diagram (fig.5 (e)) that the crystal grains of the interlocking portion are also getting smaller and finer. There are the convex and the concave portion of the interlocked area. It is similar with the result of (c), however it is more complecated compare with that of punching. From the KAM diagram (fig.5 (f)), many complecated distortions were observed in the end of seperated area by interlocking. Moreover, interlocked area is possible to contact with upper silicon steel sheet. It makes the increment of the eddy current loss. From the results, the hysteresis loss is increased by punching or interlocking after punching.

\section{Conclusions}

The magnetic characteristics affected by the residual stress of the silicon steel sheet are investigated. It was found from the IPF diagram that the crystal grains are refined by punching and interlocking. It can be seen from the KAM drawing that distortion of about $200 \mu \mathrm{m}$ is generated from the edge of the sample by punching. This is the same as the conventional knowledge that the hardness increases in the region about $1 / 2$ to 1 times the thickness at the time of punching and shearing ${ }^{9}$. The magnetic properties due to the residual stress of the silicon steel sheet were investigated. In particular, iron loss increased from $21.06 \mathrm{~W} / \mathrm{kg}$ to $29.28 \mathrm{~W} / \mathrm{kg}(39.0 \%$ increase) at $400 \mathrm{~Hz}$ from wire cutting to shrink fitting.
1. M. Croucher, Energy Policy, 45, 304 (2012)

2. M. Oka, T. Ogasawara, N. Kawano, M. Enokizono, IEEE Trans. Magn., 50, DOI: 10.1109/TMAG.2014.2319237 (2014)

3. R. Siebert, J. Schneider, E. Beyer, IEEE Trans. Magn., 50, DOI: 10.1109/TMAG.2013.2285256 (2014)

4. D. Miyagi, N. Maeda, Y. Ozeki, K. Miki, N. Takahashi, IEEE Trans. Magn., 45, 1704 (2009)

5. K. Fujisaki, R. Hirayama, T. Kawachi, S. Satou, C. Kaidou, M. Yabumoto, T. Kubota, IEEE Trans. Magn., 43, 1950 (2007)

6. K. Senda, H. Toda, M. Kawano, IEEJ Trans. Ind. Appl., 4, 496 (2015)

7. M. Yabumoto, C. Kaido, T. Wakisaka, T. Kubota, N. Suzuki, Nippon Steel Tech. Rep., 87, 57 (2003)

8. T. Nakayama, H. Kojima, JMEPEG, 16, 7 (2006)

9. K. Yun, S. Yanase, T. Ban, Y. Ohya, IEEE Trans. Mag., 53, DOI: 10.1109/TMAG.2017.2720139 (2017)

\section{References}

